\title{
"De este mar, gozado a mares, no nos sacan": aproximación a El reino errante. Poemas de la migración y el mundo árabes (1991), de Jorge García Usta
}

\author{
Nayla Chehade ${ }^{1}$ \\ University of Wisconsin
}

\section{Resumen}

Hasta ahora, con notables excepciones, pocos han sido los estudios sobre los aportes culturales de los inmigrantes árabes en Colombia. En el caso que nos interesa, nos proponemos estudiar las apuestas literarias llevadas a cabo, desde el Caribe colombiano, por uno de sus descendientes, Jorge García Usta (1960-2005), quien con su poemario El reino errante. Poemas de la migración y el mundo árabes (1991) se adentra en la afirmación de un sujeto plural y complejo, que se reconoce en su doble identidad e hibridez. Para ello tendremos en cuenta factores históricos y estéti-

\begin{abstract}
The investigations on Arab Culture contributions in Colombia have been a few, except some notable works, therefore we propose to study Arab influence in the culture of the Colombian Caribbean by one of its descendants this is Jorge Garcia Usta (1960-2005), whom at his poems El Reino Errante. Poemas de la inmigracion y el mundo Arabes speaks about the complex and plural affirmation of the subject, above all, because he knows about his hybrid and double identity. This paper we have like principal purpose
\end{abstract}

\footnotetext{
${ }^{1}$ Magíster y Doctora en Literatura Latinoamericana Contemporánea de la Universidad de Wisconsin-Madison. Actualmente se desempeña como docente del Departamento de Lenguas y Literaturas de la Universidad de Wisconsin-Whitewater. $A$ puerta cerrada, su libro de cuento, fue seleccionado en Bogotá como primer finalista del Concurso Nacional de Libro de Cuento, auspiciado por el Ministerio Colombiano de Cultura en 1997. La mayoría de estos relatos han sido publicados en diversas antologías en español y en inglés: Cuentos colombianos del siglo XXI (Indigo \& CotéFemmes, París, 2005), Cuentos cincuenta (Universidad del Valle-Cali, 2003), Letras femeninas (Asociación de Literatura Femenina Hispánica, 2002), Veinte asedios al amor y a la muerte (Ministerio de Cultura de Colombia, 1998) y Cruel fictions, cruel realities: short stories by Latin American Women Writers (Latin American Literary Review Press, 1997). e-mail: chehaden@uww.edu
}

Recibido: Marzo, 2010 - Aprobado: Junio, 2010. 
cos, así como la posible inscripción de este poemario en lo que desde hace algún tiempo se conoce como "literatura del Mahyar", o tradición de la literatura de la emigración árabe a América.

Palabras clave: poesía, inmigración árabe, identidad, sujeto híbrido, tradición del Mayhar. to show the aesthetic and historical factors and relationship with called The Mayhar Literature or tradition of literature of Arab emigration to America.

Key words: poetry, Arab immigration, identity, hybrid subject, Mayhar tradition.

Como nación mestiza, Colombia se encuentra definida culturalmente en gran parte por la amplia presencia y el impacto de diversos grupos de inmigrantes que han contribuido y siguen contribuyendo a la construcción de la identidad nacional como fenómeno cambiante, provisional, en regeneración continua. Cualquier intento de abordar el tema de la construcción de la identidad nacional tendría que incluir necesariamente un análisis detenido de los aportes de la inmigración árabe a Colombia, y aunque hasta la fecha se han publicado estudios que abordan el tema desde distintas perspectivas, la presencia árabe, así como su contribución a las diversas áreas de la cultura en Colombia, merece ser estudiada con mayor rigurosidad ${ }^{2}$. Especialmente son

\footnotetext{
${ }^{2}$ Entre los trabajos más recientes dedicados al tema de la presencia árabe en Colombia es necesario mencionar el libro de Vargas \& Suaza (2007). A través de una rigurosa investigación, las autoras rastrean la forma en que la prensa colombiana registró la presencia de palestinos, sirios y libaneses entre 1880 y1980. Documentan con ello el asentamiento de los árabes en Colombia como un proceso cuyos inicios estuvieron marcados por la discriminación y el prejuicio, y al mismo tiempo, llaman la atención sobre el impacto de los inmigrantes árabes en las principales esferas de la vida nacional. El libro no sólo provee una amplia bibliografía sobre el tema de la inmigración árabe y una extensa documentación que incluye artículos periodísticos, fotografías, testimonios, estadísticas, decretos legales y cartas, entre otros textos, sino que busca humanizar la figura del inmigrante al intercalar la investigación periodística con una suertre de crónica literaria que narra la historia de una familia sirio-libanesa radicada en Cartagena y de sus descendientes. Otras dos notables contribuciones al tema, por su rigor investigativo y su útil bibliografía, son los artículos de Restrepo Mejía (2003-2004: 180-215) y de Fawcett (1991). El artículo de Restrepo Mejía expresa claramente la necesidad de incluir el patrimonio cultural árabe en la construcción de la identidad nacional. Apoyándose en una minuciosa documentación, el ensayo ofrece una aproximación sociocultural sobre los orígenes, el proceso e impacto de la inmigración árabe en Colombia. De igual manera, el trabajo de Louise Fawcett constituye una valiosa referencia sobre los árabes en Colombia y su proceso de adaptación y asimilación, así como su impacto general en la sociedad colombiana.
} 
necesarios estudios que ofrezcan una visión más compleja de la inmigración árabe, que contextualicen sus aportes y trasciendan la representación estereotipada y reduccionista que resalta, sobre todo, la imagen del comerciante ambulante o buhonero, y que se ha seguido reproduciendo incluso desde la literatura.

Vale la pena mencionar que en Colombia las políticas estatales decimonónicas, y de principios del siglo XX con respecto a la inmigración, fueron selectivas y buscaban deliberadamente atraer inmigrantes europeos con el propósito de "civilizar" la sociedad, aumentar la población blanca e impulsar el desarrollo material y la modernización del país ${ }^{3}$. A pesar de que los inmigrantes de origen árabe no encajaban en este esquema, y de que los retos geográficos, los rigores del clima, la dificultad en las comunicaciones, la inestabilidad política y las guerras civiles continuas convirtieron a Colombia en un destino menor para los inmigrantes en general, durante las últimas dos décadas del siglo XIX y las primeras del siglo XX (igual que la mayor parte del continente latinoamericano) el país fue escenario de la llegada de un número considerable de inmigrantes sirio-libaneses y palestinos, que se establecieron en ciudades y pueblos a lo largo y ancho de su geografía, pero especialmente en la costa caribeña, donde se encontraban los primeros puertos de entrada al país ${ }^{4}$. Casi todos eran cristianos, e inicialmente los que formaron parte de la primera ola de inmigrantes -la "etapa pionera" o de los "fundadores",

\footnotetext{
${ }^{3}$ Como lo señala Restrepo Mejía: "Dos eran los objetivos concretos que se buscaban con estas políticas. Por una parte se pensaba que era necesario 'civilizar' la sociedad, es decir, 'europeizarla' en sus costumbres y aumentar la población de raza blanca. Por otra parte se creía que la modernización material debía estar a cargo de extranjeros competentes que abrieran carreteras, desarrollaran la navegación y así favorecieran la colonización agrícola y resolvieran el supuesto problema de la escasez de población en un territorio casi desconocido." (2003-2004: 184). Viloria de la Hoz (2004), por su parte, cita un escrito del periódico cartagenero El Espía, fechado en enero de 1915, que ilustra de manera clara la actitud hostil, abiertamente racista, hacia los primeros inmigrantes árabes: "La expulsión de los turcos es una necesidad imperiosa [...] Nosotros debemos limpiar la ciudad, no dejar en ella ningún elemento perjudicial y tenerla dispuesta para recibir razas como la belga, por ejemplo, portadora de la civilización, el progreso y la cultura" (26-27).

${ }^{4}$ El citado trabajo de Viloria de la Hoz (2004), además de proveer un breve recuento de los antecedentes históricos que impulsaron la diáspora árabe, se enfoca en el estudio de la inmigración árabe en la zona del Caribe colombiano como espacio propicio para la actividad comercial debido a la intensa actividad de sus puertos marítimos y fluviales. Destaca las huellas de los inmigrantes árabes en la economía y en la arquitectura de la región en un texto bien documentado que incluye un estudio de caso, tablas con datos específicos sobre la incursión de los comerciantes árabes en diversas empresas económicas y una útil bibliografía.
} 
como se le ha llamado (1880 y 1920) ${ }^{5}$ - provenían de la región de Siria, que bajo el dominio del Imperio Otomano incluía también los territorios actuales del Líbano y Palestina.

Los "turcos", como se les llamó erróneamente a estos inmigrantes por llevar pasaporte turco -símbolo de la opresión de la que muchos huían-, continuaron llegando después de la Primera Guerra Mundial y de la disolución oficial del Imperio Otomano, durante lo que se ha llamado "la etapa intermedia", ubicada entre las dos guerras mundiales, hasta 1945, bajo los mandatos británico (Palestina) y francés (Siria y El Líbano). Durante esta época, los movimientos de oposición a la presencia europea y la búsqueda de independencia incrementaron la represión en la región y contribuyeron al deterioro de la economía local y al consiguiente aumento en la inmigración. En esta periodización de la diáspora de libaneses, sirios y palestinos, se ha señalado también una tercera etapa, la "contemporánea" o "actual", que se extiende desde la Segunda Guerra mundial hasta el fin de la guerra civil en el Líbano (1945-1990).

De cualquier manera, entre las causas de esta inmigración masiva se han señalado como determinantes razones de carácter religioso, político y económico, directamente relacionadas con las transformaciones sociopolíticas ocurridas en la región en los últimos 120 años ${ }^{6}$. En Colombia, la mayoría de estos inmigrantes se radicaron en las ciudades y pueblos de la costa Atlántica, como se mencionó, pero también se establecieron en casi todas las regiones del país, donde su presencia no sólo transformaba el ámbito social, cultural y económico del área donde vivían, sino que a la vez los transformaba a ellos y a sus descendientes. Casi todos lo inmigrantes de la etapa inicial se dedicaron al comercio ambulante hasta que lograron abrir propios establecimientos, y en poco tiempo pudieron a su vez incursionar prácticamente en todas las actividades económicas del país, desde la explotación del caucho y del oro, la ganadería y la agricultura, hasta el desarrollo de los sistemas de transporte.

\footnotetext{
${ }^{5}$ La periodización de la inmigración árabe a Colombia en tres etapas o períodos que se inician a partir de 1880, año en que se registró la llegada de los primeros inmigrantes árabes a Colombia, es común. Restrepo Mejía (2003-2004: 193) la emplea, citándola a su vez del trabajo de Behayne (1980).

${ }^{6}$ Aunque, como anota García Usta, es necesario tener en cuenta que "La imagen del árabe errante es anterior a la presencia árabe en América. Su ancestral ejercicio del comercio, sus expediciones de colonización y conquista [...] se suman al nuevo proceso migratorio iniciado en 1860 y al drama particular de la nación palestina para reforzar esta imagen intemporal de la enrancia [...]" (1997: 139).
} 
Inicialmente prefirieron los matrimonios endogámicos, pero pronto la costumbre se relajó y dio paso a los enlaces exogámicos. Como la mayoría eran cristianos -ortodoxos, católicos o maronitas, en menor número-, y los motivaba una clara voluntad de adaptación, la religión no constituyó un obstáculo para la integración. En consecuencia, no les fue difícil adoptar las prácticas católicas imperantes en el país, y debe decirse que lo hicieron de una forma bastante flexible y secular. Si bien una gran parte de los primeros inmigrantes siriolibaneses y palestinos carecían de educación formal, muchos de los hijos de las generaciones pioneras asistieron a universidades e incursionaron en el campo de la política y del servicio público. Muchos eligieron, así mismo, la práctica del arte en sus distintas manifestaciones como forma de vida. Jorge García Usta, poeta del caribe colombiano, ejemplifica claramente esta vertiente de los numerosos descendientes de inmigrantes árabes que se dedicaron por entero al quehacer literario y que han impactado con su obra la tradición literaria colombiana.

\section{II}

Jorge garcía Usta nació en 1960 en Ciénaga de Oro, un pueblo del Caribe colombiano, con un nombre tan lírico que parece sacado de una de las imágenes de sus propios poemas, y murió prematuramente a los 45 años de edad en Cartagena de Indias, la ciudad donde se desempeñó, entre otros oficios, como periodista, editor, ensayista y gestor cultural, y donde ejerció la poesía y el periodismo con una vehemencia, un rigor crítico y un sentido de responsabilidad social proverbiales ${ }^{7}$. Profundamente comprometido con el desciframiento y la revaluación del entorno caribeño, sobre todo en su preocupación por incluir en el marco de la cultura del Caribe el aporte de grupos y comunidades mantenidos al margen, su trabajo en el campo de la crítica literaria y de la investigación cultural, como lo anota Cristo Figueroa, "es referencia obligada para conocer los procesos secretos y las dinámicas ocultas o silenciadas de la cultura del Caribe colombiano en relación con el devenir nacional y de otras latitudes" (2005-2006: 1).

\footnotetext{
${ }^{7}$ Aguaita, Revista del Observatorio del Caribe Colombiano, de la que García Usta fue editor hasta su muerte, contiene en el n 13-14 (2005-2006) una serie de artículos y ensayos publicados en homenaje al poeta después de su muerte. Estos trabajos abordan las distintas facetas creadoras del escritor y destacan la rigurosidad de su trabajo, su habilidad para incorporar las preocupaciones sociales al terreno artístico, así como su impacto en la investigación sobre la cultura de la región del Caribe colombiano.
} 
De igual modo, al abordar su quehacer como poeta, es preciso afirmar que García Usta alcanzó a producir una obra poética rigurosamente pulida, con innegable registro propio y amplio aliento, que traspasa lo local y convierte su labor literaria en referencia imprescindible dentro del marco de la poesía hispanoamericana. El poeta Rómulo Bustos Aguirre sitúa a García Usta en Colombia dentro de la que "[...] bien pudiéramos llamar la generación invisible, conformada por poetas nacidos en los 50 y en los 60 y cuya producción comienza a circular a partir de los 80." (2007: 10). Bustos Aguirre indica también, muy acertadamente, que a través de su legado poético, García Usta logra construir lo que ha llamado la "épica de lo cotidiano" o el "heroísmo de lo cotidiano y anónimo" (11), estrategia discursiva y temática que permite al poeta historiar o cantar lo que no tiene historia registrada, oficializada, pero que, paradójicamente, se cimienta también en un eje dramático capaz de indagar sobre la condición humana en sus más diversos aspectos. Parte de esta voluntad de historiar poéticamente el ámbito de lo cotidiano ${ }^{8}$, presente también en su obra periodística, la manifiesta García Usta en el poemario El reino errante. Poemas de la migración y el mundo árabes (1991)․

Es necesario mencionar que entre las muchas vertientes culturales y referentes espaciales que confluyen en esta colección, se destaca de modo evidente, por un lado, el mundo del Caribe, epicentro del trabajo de García Usta en todas las áreas, y por otro, el aspecto que quisiera destacar la herencia árabe, que le llega directamente por línea materna ${ }^{10}$. Ambos componentes se manifiestan continuamente en el texto como referentes construidos simbólicamente a través de

\footnotetext{
${ }^{8}$ Alberto Salcedo Ramos, en "Una flor para Jorge García Usta: aproximación fraternal a su obra periodística", expande una idea similar y la aplica al trabajo periodístico de García Usta, al afirmar que para éste, periodismo y poesía no son prácticas excluyentes en la vida diaria. Afirma Salcedo Ramos: "Más de una vez le oí decir a Jorge que la poesía -necesaria para dignificar el periodismo- va más allá del lenguaje: es saber buscar lo grandioso de lo simple, lo sublime de lo cotidiano. Él hablaba -recuerdo- de una "poesía situacional," que es aquella que subyace en las acciones meas elementales de los hombres" (2005-2006: 6).

${ }^{9}$ A esta edición pertenecen los poemas del autor citados a lo largo del presente trabajo.

${ }^{10}$ La madre del poeta, Nevija Usta Zaruf, fue hija de un artesano de Damasco que se estableció a comienzos del siglo XX en el Valle del Sinú, en el Caribe colombiano, y de Esquilla Zaruf, también inmigrante árabe. En más de una ocasión, García Usta alude al impacto de su ancestro árabe en su formación: "Por la familia paterna, hay una sólida vocación la música, las matemáticas y la pedagogía. Por la materna, una palabra oral espléndida, un sentido de contar cosas, un sentido de pertenencia tribal que está en las bases más primitivas y sólidas de nuestra cultura" (citado por Díaz, 2007: 23-1).
} 
imágenes recurrentes-el mar, el desierto, la luna o los mostradores del comerciante, por ejemplo-y de situaciones emblemáticas -la partida y la llegada, el ritual del trabajo diario y de las comidas, las soledades y los encuentros, entre muchas otras, que se convierten en alegoría emotiva de dos universos significantes-. En esta aproximación analizo de qué manera en El reino errante. Poemas de la migración y el mundo árabes, García Usta indaga en la ancestralidad árabe y reinterpreta poéticamente el fenómeno de la doble identidad como síntesis o compendio de dos mundos alegóricos que se interceptan y reconcilian en la creación de un nuevo sujeto híbrido.

\section{III}

El análisis de la producción poética de algunos de los poetas colombianos de origen árabe muestra que éstos manifiestan de distintas formas, y en diverso grado, la presencia e impacto del ancestro árabe en su obra -casi siempre evidenciando un sentimiento de pérdida atávica que se traduce en nostalgia- como es el caso de Meira Del$\operatorname{mar}^{11}$, o de huella existencial fatalista, como se observa en varios de los poemas del controversial Raúl Gómez Jattin ${ }^{12}$, para mencionar sólo algunos de los más representativos. Es preciso indicar, no obstante, que Jorge García Usta es el único que hasta ahora ha dedicado un poemario completo al tema, hecho que pone de manifiesto el lugar privilegiado que esta vertiente cultural ocupa en su obra.

En el poemario, construido siguiendo un hilo narrativo que se extiende casi por un siglo en poemas estratégicamente fechados, García Usta logra delinear arquetipos que representan hitos en la

\footnotetext{
${ }^{11}$ La nostalgia que reiteradamente se observa en la obra de Meira Delmar se ha relacionado con la presencia de un significado que el hablante poético no logra descifrar, ya que se desplaza continuamente y tiene que ver con una raíz ancestral perdida en el tiempo. Se trata de un desprendimiento atávico de presencias y espacios nunca experimentados de primera mano, pero reconstruidos y adivinados desde el tiempo y la distancia por la vía emotiva, y decantados por la imaginación poética. Muy significativamente el hablante poético en "Ayer", aparecido en la colección Reencuentro, enuncia: "Dentro de mí, creciendo siempre oigo/ un oleaje de siglos". Respecto a la función de la nostalgia en la obra de Meira Delmar, véase Chehade (2003).

${ }^{12}$ En el poema "Un fuego ebrio de las montañas del Líbano", en el que el hablante poético se dirige a su madre, la presencia ancestral árabe se asume de forma fatalista: "Yo te sé de memoria Dama enlutada/ Señora de mi noche Verdugo de mi día/ En ti están las fuentes de mi melancolía/ Y del fervor de estos versos/ En ti circula un fuego ebrio de las montañas del Líbano/ En mí vapores densos de tu delirio nublan mi mediocre/ razón española/ Madre yo te perdono el haberme traído al mundo/ Aunque el mundo no me reconcilie contigo" (Gómez Jattin, 2004: 4).
} 
historia de la diáspora árabe en Colombia desde una voz poética que se desdobla progresivamente en tiempo. En esta colección el hablante poético se humaniza y se define mediante figuras con nombre propio y apellido, y lo narrativo se enlaza fructíferamente con lo lírico en imágenes trabajadas con meticulosidad y elocuencia. Estas imágenes dan cuenta, emblemáticamente, de la experiencia de la inmigración árabe a tierras colombianas como crónica dual de desarraigo y afincamiento, desprendimiento y encuentro, asombros, pesares e intercambios gozosos en una dimensión que trasciende la perspectiva de la experiencia árabe y la extiende a la búsqueda universal de felicidad y bienestar. Consecuentemente, la colección se inicia con el poema que representa el comienzo del éxodo: "La salida, en el camino de Damasco a Beirut (1887)," en el cual el hablante poético se prepara para dejar su tierra y enfrentarse con lo desconocido, con muy pocas pertenencias y con el recuerdo como posesión más preciada: "Rauf, alista tus ojos./ Llevaremos lo que, ahora, somos:/ una maleta, cuatro cuerpos/ y memorias" (5). El hablante poético se define a partir de la memoria, que se presenta como el elemento que lo constituye como sujeto y, por extensión, a los suyos.

Pero si en este enunciado está presente el dolor del desarraigo, también habita en él una resolución explícita de aceptación de lo nuevo. En el momento dela marcha, el ser no se presenta como entidad estática, ya que lo condiciona el "ahora" que modifica al "somos" y hace que se muestre abierto a la posibilidad de cambio, al "seremos" del futuro. No en vano, en el momento de la llegada al espacio del Caribe, la contemplación del mar prefigura la comunión con el nuevo ámbito. "Oh, este mar trae a mis almas/ un lugar unitario", dice la voz poética en "Primera noción del mar de Nabil Barbur en Cartagena de Indias (1910)" (7), y el poema concluye con la exaltación de sus efectos reparadores, en un enunciado que implica la vinculación afectiva con el lugar de acogida: "Se te acaban las miserias con el mar inmediato" (Ibíd.).

De esta manera, García Usta construye una "crónica" de lirismo sostenido, destacando la relación dialéctica entre el mundo de la cultura ancestral árabe y el de la región Caribe, más que desde el énfasis en la exclusión o pérdida de elementos, acentuando de qué forma las estrategias que los sujetos representados elaboran para ajustarse y responder a la nueva situación cultural y espacial sirven de base para la creación de complejas y fructíferas identidades. A lo largo de El reino errante -poemario que es, a la vez, homenaje, epopeya y cosmogonía- es necesario indicar que existen también concesiones a la nostalgia y al desprendimiento de un mundo 
ancestral que la voz poética percibe a la distancia, matizado por el paso del tiempo y rescatado a través de imágenes: "Volveremos/ a vernos/ tal vez, en dos mil años/ y no seré Elías, su padre,/ sino un brillo gastado por la ausencia", dice el padre al hijo que emigra en el momento de la despedida en el poema "Consejos de Elías Rumié a su hijo (1890)" (6). Y en "De una carta de Abraham Gedeón a su padre en Aleppo (1924)", el hablante poético enuncia: "Recuerdo de mi abuelo/ el opaco desembarco./ Una palabra lisa sobre el honor/ como única pertenencia./ Una sucesión de orgullos/ estratégicos, solares./ Y aquella mano, ya página de polvo,/ alentando, sin embargo, la crin del alazán" (14).

Igualmente, la voz poética lamenta la pérdida del mundo anterior y su soledad en el presente en "Declaración de amor de Demetrio Spath (1934): "No sé cómo vine/ a estas tierras tan anchas./ Las voces son más solas,/ los cielos más ansiosos" (15). No obstante, el tono del poemario sobrepasa explícitamente el regodeo nostálgico y la queja centrada en la pérdida: "Yo no me limito a conocer las cuentas del pasado/ a adorar el número impar, los milenios de camello./ A certificar a tanto señor notorio/ el llanto de mi orígen, la compañía de mis párpados/ Qué soledad he pagado entre profusos armarios" ("José Fadul habla de su presente en la calle larga de Cartagena de Indias (1919)” (13), evidenciando un deseo de vinculación e integración del sujeto al nuevo espacio (hecho que constituye uno de los rasgos más sobresalientes del texto y que se acentúa progresivamente a lo largo del mismo).

Es posible observar cómo, con imágenes y referencias que se establecen como símbolos concisos de dos universos diferentes -y mediante pequeños poemas-relatos-, la voz poética recoge prácticas y productos culturales de distinta naturaleza que emblematizan el "aquí" y el "allá", y los muestra chocando, interrelacionándose, coexistiendo, contradiciéndose y redefiniéndose en una afortunada síntesis dentro del marco cultural del Caribe colombiano. La retrospección da paso a la reafirmación y la comunión de mundos es así cada vez más estrecha. José Fadúl sobrepasa la tentación de la nostalgia y del lamento, expresando con convicción su pertenencia al nuevo espacio, y en su enunciado las distancias se disipan, los espacios se asemejan y los individuos se nivelan en una lucha común:

En la noche paladeo

la espera en los aceites

y veo cómo ya el mar me ama

en mi propia sed.

Así en Beirut como en Cartagena de Indias: 


\author{
un aire enjoyado pule \\ las grandes ocasiones \\ y los hombres tallan y se ganan \\ en la molicie del sudor \\ cada yarda de su asombro.
}

La investigadora chilena María Olga Samamé (2006) enmarca este poemario en la tradición de la literatura de la emigración árabe a América, conocida también como "literatura del Mahyar", cuyas raíces se vinculan al trabajo de poetas como Gibrán Khalil Gibrán y otros escritores árabes emigrados a los Estados Unidos, y que según explica Samamé: "lleva la triple impronta de la nostalgia, del pensamiento y de la libertad" (9). Los poetas del Malhyar -quienes inicialmente continuaron escribiendo en árabe y luego, al carecer sus descendientes del entrenamiento formal en la lengua de sus antepasados, pasaron a usar la del país de acogida- muestran explícitamente una preocupación por recuperar la memoria ancestral, intentando comprender su presente y abordar su identidad dual. Construye, anota Samané, "una escritura basada en experiencias personales, expresan el dolor social y colectivo con impronta metafísica, expresionista y simbolista occidental, y se proponen entregar un mensaje directo, personal y profundo [...]" (10).

El sugerente análisis de Samamé enriquece la lectura del poemario de García Usta, en la medida en que éste responde a los planteamientos de la literatura del Mahyar, delineados por la mencionada crítica. Podemos encontrar sin duda en esta colección (como ya lo hemos indicado) el sesgo nostálgico en las alusiones a un mundo irrecuperable, la reflexión existencial en la búsqueda de sentido motivada por la trashumancia y el exilio, y una clara noción de compromiso con la equidad y la justicia social, tanto para los sujetos trasplantados al nuevo espacio, como para una causa que trasciende las fronteras locales: la del pueblo palestino ${ }^{13}$. Sin embargo, quisiera enfatizar que veo en los hermosos poemas del El reino errante, ante todo, una voluntad explícita de reafirmación del nuevo sujeto, que se mira a sí mismo como individuo más favorecido que escindido, más complejo y rico, que fracturado o desgarrado, punto de encuentro o confluencia de tradiciones culturales que van reinventándose en el proceso

\footnotetext{
${ }^{13}$ Respecto a la solidaridad de García Usta con la causa palestina y su denuncia de los atropellos sufridos históricamente por este pueblo, veánse los poemas "Jerusalén: semblanza de Salím Muvdi (1970)” (26), “Trópicos para Mahmud Darwish” (38) y "En un muro de Shatila" (39).
} 
amalgamiento, a partir de la inusitada "maroma de las mezclas" (20) que tiene lugar en el espacio que lo acoge, para usar uno de los versos del propio García Usta.

De esta manera, releo el poemario de García Usta a la luz de los enunciados del escritor libanés, residente en Francia, Amin Maalouf, al reflexionar sobre la identidad de los sujetos que llama "fronterizos". Es decir aquellos que, como él mismo, viven la fricción continua de navegar entre varias pertenencias culturales, sean éstas de carácter étnico, religioso, político, lingüístico, socioeconómico o de orientación sexual, para mencionar sólo algunas, y de verse forzados muchas veces a elegir entre unas y otras. Su libro Identidades asesinas (1999) es un intento de comprender conductas extremas, basadas según Maalouf, en situaciones persistentes de injusticia social y en la consiguiente adhesión incondicional del sujeto a una sola de sus pertenencias por encima de las demás. Se trata así de una condena a la "concepción estrecha, exclusivista, beata y simplista que reduce toda identidad a una sola pertenencia que se proclama con pasión" (13).

No obstante, el libro de Maalouf es más que nada una apuesta optimista a la capacidad de los sujetos "fronterizos" de asumir sus múltiples pertenencias culturales como privilegio y de hacerlo valer en la sociedad en que viven para, en palabras del autor, "tejer lazos de unión", "allanar, reconciliar" y ante todo, entender que "su vocación es ser enlaces, puentes, mediadores entre las diversas comunidades y las diversas culturas" (12-3). En El reino errante, Jorge García Usta rescata, desde la especificad de su propia experiencia, su vinculación al acervo árabe heredado de sus ancestros maternos, pero al mismo tiempo enfatiza una clara voluntad ecuménica, un deseo evidente de revalidar su identidad plural a partir de la perspectiva del sujeto híbrido que encarna en sí mismo la habilidad de sintetizar mundos distintos y de tejer puentes entre ellos.

Desde las voces diversas de los emigrados y sus descendientes, que transitan en las páginas de su poemario testimoniando sus batallas cotidianas y sus pequeños triunfos, García Usta expresa esperanzadoramente la creación de una amalgama nueva de culturas como una realidad plausible, basada en la posibilidad de los sujetos "fronterizos" de abstraer simbólicamente elementos representativos de culturas al parecer disímiles y distantes y de reclamar sus componentes como pertenencias valiosas. En última instancia, se trata de un entrecruzamiento de viejas sabidurías: "Indios desnudos en las prieturas del mundo/ nos daban a beber las filosofías del cáñamo/, el habla de un maíz tan antiguo/ como la disciplina del desierto", escuchamos al hablante poético en el poema 
“Bechara Chalela narra la entrada al Sinú (1910)" (9), y concluye con el reconocimiento explícito de un nuevo producto humano que reconoce su naturaleza plural y la complejidad de la misma, asumiéndola sin fricciones y con un abierto sentido de pertenencia a la realidad local. De este modo, la voz poética expresa claramente "Soy hijo de esta aguas/ centro de sus nuevos enigmas/ mi palabra sabe ya insultar al verano" (Ibíd.).

Hay en los poemas de esta colección, consecuentemente, un empeño en desterrar el prejuicio que enfatiza las diferencias culturales entre los emigrados y el ámbito que los acoge, y en reiterar que en toda práctica cultural, por disímil que parezca, la similitud puede ser mayor que la aparente diferencia. Así, en "Samir Saer mira bailar en las Antillas (1915)", la voz poética alcanza a reconocerse en la efervescencia del baile caribeño: "En estas tierras tan anchas todo es tristeza y baile/ pradera y baile,/ presagio y baile./ Si la noche está herida, bailan./ Si el caimán se aloca, bailan./ Bailan porque el mar/ y porque la muerte" (10). Y aunque el ritmo sea ajeno, la fuerza que lo motiva es familiar: "Nos invitan a bailar pero no podemos./ Claro que nuestro primer mundo/ conoce este fuego:/ El ritmo proviene de las sierpes del viento/ de los caballos que fluyen como talismanes,/ de las muchachas que se niegan como lunas ostentosas" (10-1).

En el esmero por recuperar el detalle y en la mirada que recoge el acto mínimo y repetido, García Usta humaniza la figura del inmigrante y dignifica su empresa, alejándola del estereotipo. En "Acto de fe de Antonio Gossaín (1918)", dice el hablante poético: "De aquí,/ de este mar gozado a mares,/ de esta luz que enjoya todo cuerpo,/ de este viento que embala el deseo,/ de este mostrador con cicatrices de hombre/ y ojo de ortiga,/ de esta locura portuaria del día/ no nos sacan/ no nos sacan" (12). La voz poética reitera su enlace emocional con el entorno Caribe y la gratificación que recibe de su espléndido escenario. Se enfatiza de esta manera la voluntad expresa de arraigo como parte vital de la experiencia del inmigrante árabe trasplantado al Caribe, así como el reconocimiento emotivo del nuevo espacio y del derecho a cohabitarlo ganado por el empeño, el esfuerzo diario y la voluntad inquebrantable. En retribución, la comunión de los mundos será cada vez más estrecha.

En "La calle de los Turcos: noción de julio Dumar (1936)", el acercamiento al arraigo se da a partir del espacio y la mirada del otro: "Y la negra que ve el rostro del árabe/ se acuerda de un tío remoto/ que también lloró/ sobre las arenas rigurosas" (16), en un enunciado donde se borran las fronteras raciales y se comparte una experiencia común y dolorosa resuelta en el encuentro gozoso de los cuerpos: 
"Hemos visto las primeras nalgas de mujer criolla./ Un color de tinaja./ Vellos como espléndidos atavíos./ La miel y el surco” (16). Así, el intercambio amoroso y el disfrute del erotismo renovado hacen que el arraigo se perciba como una realidad cada vez más definitiva y el desprendimiento original como una memoria integrada al nuevo espacio.

En “Jorge Baladí habla de las fronteras abolidas (1950)”, del deseo de integración se pasa a la fusión completa, al entrecruzamiento que se produce en el nuevo sujeto, reinventado como síntesis plural o suma de tradiciones. En este poema la voz poética prescinde de la nostalgia, de la comparación y del contraste de realidades. Dice, victoriosa: "Aquí canta el ají de la algarabía/ en las patrias finales,/ la maroma de las mezclas,/ el misterio de los marasmos/ navegando entre las islas hostiles", y enuncia el fin de la enrancia, porque: "La sangre cruza, ya revuelta,/ entre la nación que fulgura/ en sus nuevas, fértiles pesadumbres/ Toda voz/ es, ahora, una fusión de ríos./ Todo cuerpo,/ un lugar de encuentro./ La memoria, esa amorosa quema de fronteras" (20).

En El reino errante, García Usta transforma el desprendimiento de la raíz ancestral en empresa fundacional de la que deriva un nuevo sujeto híbrido, de naturaleza plural, síntesis o compendio de tradiciones que, en última instancia, se asumen abiertamente. El poeta cartagenero propone el mundo iluminado y contradictorio del Caribe como el escenario propicio en que confluyen, se cultivan, interceptan y fusionan, sueños, pesares, deseos y realidades provenientes de las más variadas latitudes y de las más antiguas raigambres. El Caribe que se desprende de las páginas de El reino errante sorprende en su belleza irreal y lastima en el devenir de su historia, pero sobre todo, acoge, recrea y reinventa sujetos, propiciando el nacimiento de nuevas identidades.

\section{Bibliografía}

Behayne, G. (1980). "Anotaciones sobre inmigraciones libanesas a Colombia”, Revista Javeriana, $\mathrm{n}^{\circ} 467$ (Agosto).

Bustos Aguirre, R. (2007). "Jorge García Usta: de la imaginación épica a la imaginación dramática”. En García Usta, Jorge. El fuego que perdura (Antología poética). Cartagena: Universidad de Cartagena.

Chehade, N. (2003). " 'Y se me va llenando/ de nostalgia la vida': Meira delmar, voz de aliento inquebrantable". En Jaramillo, M. M; Osrio, Betty \& Castillo Mier, A. (Eds.). (2003). Poesía y prosa de Meira Delmar. Barranquilla: Universidad del Norte. 
Díaz, J. C. (2007). "Homenaje a Jorge Garcóia Usta”, Termita Caribe. Revista Iberoamericana de Arte y Literatura, n 34, en http:// termitacaribe.blogspot.com/2007/01/jorge-garca-usta.html

Fawcett, L. (1991). "Libaneses, palestinos y sirios en Colombia”, Documentos, $\mathrm{n}^{\circ}$ 9, Barranquilla, Universidad del Norte.

Figueroa, C. (2005-2006). Aguaita, Cartagena, Observatorio del Caribe Colombiano, $\mathrm{n}^{\circ}$ 13-14.

García Usta, J. (1991). El reino errante. Poemas de la migración y el mundo árabes. Cartagena: Litografía Jonán.

- (1997). "Los árabes en Macondo", Deslinde, n²1 (JulioSeptiembre), pp. 123-139

Gómez Jattin, R. (2004). Amanecer en el Valle del Sinú (Antología poética). Bogotá: Fondo de Cultura Económica.

Maalouf, A. (1999). Identidades asesinas. Madrid: Alianza Editorial.

Restrepo Mejía, I. (2003-2004). “Migración árabe en Colombia: un encuentro entre dos mundos", OASIS, Bogotá, Universidad Externado de Colombia, CIPE, pp. 180-215.

Salcedo Ramos, A. (2005-2006). "Una flor para Jorge García Usta: aproximación fraternal a su obra periodística”, Aguaita, Cartagena, Observatorio del Caribe colombiano, $\mathrm{n}^{\circ}$ 13-14.

Samané, M. O. (2006). "La poesía del Mahyar o de la emigración árabe a Chile y a Colombia, a través de los poetas Mahfud Massís y Jorge garcía Usta", Taller de Letras, $\mathrm{n}^{\circ}$ 39, pp. 9-24.

Vargas, P. \& Suaza, L.M. (2007). Los árabes en Colombia. Del rechazo a la integración. Bogotá: Planeta.

Viloria de la Hoz, J. (2004). Los"turcos" de Lorica: presencia de los árabes en el Caribe colombiano. Bogotá: Universidad de Los Andes. 